\title{
Pengaruh Variasi Media Pendingin Pada Material Baja Karbon Rendah Terhadap Kekuatan Pengelasan Posisi 1G
}

\author{
Lukman Triawan $^{(1)^{*}}$, Muh Thohirin $^{(2)}$, Agus Apriyanto ${ }^{(3)}$ \\ ${ }^{(1)}$ Universitas Sang Bumi Ruwa Jurai, ${ }^{(2)}$ Universitas Sang Bumi Ruwa Jurai, ${ }^{(3)}$ Universitas Sang Bumi Ruwa Jurai \\ email korespondensi: lukman3awan@gmail.com ${ }^{1 *}$, muhtohirin21@gmail.com ${ }^{2}$,agus.apriyanto89@gmail.com ${ }^{3}$
}

\begin{abstract}
Abstrak.
Di dalam dunia pengelasan atau dunia industri saat ini baja karbon rendah merupakan salah satu logam yang sering digunakan dalam pembangunan konstruksi. Salah satu masalah yang sering terjadi dalam penggunaan baja sebagai bahan dasar konstruksi adalah baja mempunyai sifat yang mudah mengalami patahan. Tujuan Penelitian ini adalah untuk memperoleh hasil tentang analisis besarnya kekuatan Uji Bending baja karbon rendah yang telah mengalami pengelasan SMAW dengan variasi pendinginan. hasil pengelasan SMAW dengan variasi pendinginan pengelasan menggunakan elektroda LB-52U. Penelitian ini menggunakan metode penelitian eksperimental. Data yang diperoleh dianalisis menggunakan analisis deskriptif, yakni menjabarkan perbandingan spesimen yang diberi perlakuan secara berbeda-beda ketika proses pendinginan. Nilai dari hasil uji Pendinginan setiap spesimen, Uji Bending kemudian dianalisis. setiap variasi pendinginan diambil 1 spesimen Uji Bending logam las dan logam induk. Objek penelitian pengelasan yang dipakai adalah baja karbon rendah. Spesimen uji bending mengacu pada standar ISO 178:2003 Bending Three Point. Hasil penelitian diperoleh Kekuatan lentur sambungan las. Nilai kekuatan lentur dengan pendingan dengan media Oli yaitu 32118,16 N. Sedangkan dengan Pendinginan Air Coolant mengalami Penurunan 13144,9 N dan pada pendinginan dengan Air mengalami Penurunan7950,92 N Struktur mikro logam induk terdiri dari perlit dan ferrit, struktur mikro daerah HAZ. Pengdinginan dengan Variasi Oli, Coolant dan Air. Struktur mikro daerah HAZ dan logam las dengan kuat arus pengelasan 70 dan 80 Ampere terdiri dari austenit sisa dan widmanstatten ferrite.
\end{abstract}

Kata Kunci: Sifat Mekanik, Uji Bending, Pengelasan SMAW, Baja Karbon Rendah

\begin{abstract}
.
In the world of welding or the industrial world today, low carbon steel is one of the metals that is often used in construction. One of the problems that often occurs in the use of steel as a basic construction material is that steel is prone to fracture. The purpose of this study was to obtain results about the analysis of the magnitude of the bending test strength of low carbon steel that has undergone SMAW welding with variations in cooling. SMAW welding results with variations in welding cooling using LB-52U electrodes. This study uses experimental research methods. The data obtained were analyzed using descriptive analysis, which describes the comparison of specimens treated differently during the cooling process. The value of the cooling test results for each specimen, the bending test was then analyzed. For each cooling variation, 1 specimen of the Bending Test of the weld metal and the parent metal was taken. The object of welding research used is low carbon steel. The bending test specimen refers to the ISO 178:2003 Three Point Bending standard. The results obtained by the flexural strength of the welded joint. The value of flexural strength by cooling with oil media is $32118.16 \mathrm{~N}$. Meanwhile, by cooling with water coolant it decreases by $13144.9 \mathrm{~N}$ and on cooling with water it decreases by $7950.92 \mathrm{~N}$. The microstructure of the parent metal consists of pearlite and ferrite, the microstructure of the HAZ region. Cooling with Variations of Oil, Coolant and Water. The microstructure of the $H A Z$ region and the weld metal with a welding current of 70 and 80 Ampere consisted of residual austenite and widmanstatten ferrite.
\end{abstract}

Keywords: Mechanical Properties, Bending Test, SMAW Welding, Low Carbon Steel

\section{PENDAHULUAN}

Perkembangan dan kemjuan industri yang menyangkut logam atau baja, khususnya bidang pembangunan dengan menggunakan pengelasan dibutuhkan berbagai penelitian agar dapat sambungan las yang bermutu tinggi, karena menyangkut keselamatan dan umur pakai. Seiring dengan pemakaian sambungan las baja yang semakin meningkat, maka 
teknologi proses yang berkaitan dengan perubahan sifat dan karakteristik memiliki peranan yang yang tak kalah pentingnya.

Faktor yang mempengaruhi las adalah prosedur pengelasan yaitu suatu perencanaan untuk pelaksanaan penelitian yang meliputi cara pembuatan konstruksi las yang sesuai rencana dan spesifikasi dengan menentukan semua hal yang diperlukan dalam pelaksanaan tersebut. Faktor produksi pengelasan adalah jadwal pembuatan, proses pembuatan, alat dan bahan yang diperlukan, urutan pelaksanaan, persiapan pengelasan (meliputi: pemilihan mesin las, penunjukan juru las, pemilihan elektroda, penggunaan jenis kampuh) (Wiryosumarto, 1988).

Pengelasan berdasarkan klasifikasi cara kerja dapat dibagi dalam tiga kelompok yaitu pengelasan cair, pengelasan tekan, dan pematrian. Pengelasan cair adalah suatu cara pengelasan dimana benda yang akan disambung diapanaskan sampai mencair dengan sumber energi panas. Cara pengelasan yang paling banyak digunakan adalah pengelasan cair dengan busur (las busur listrik) dan gas. Jenis las busur listrik ada 4 yaitu las busur dengan elektroda terbungkus, las busur gas (TIG, MIG, las busur CO2), las busur tanpa gas, las busur rendam. Jenis dari las busur elektroda terbungkus salah satunya adalah las SMAW (Shielding Metal Arc Welding) (Wiryosumarto, 1988).

Mesin las SMAW menurut arusnya dibedakan menjadi tiga macam yaitu mesin las arus searah atau Direct Current (DC), mesin las arus bolak-balik atau Alternating Current (AC) dan mesin las arus ganda yang merupakan mesin las yang dapat digunakan untuk pengelasan dengan arus searah (DC) dan pengelasan dengan arus bolak-balik (AC). Mesin las arus DC dapat digunakan dengan dua cara yaitu polaritas lurus dan polaritas terbalik. Mesin las DC polaritas lurus (DC-) digunakan bila titik cair bahan induk tinggi dan kapasitas besar, untuk pemegang elektrodanya dihubungkan dengan kutub negatif dan logam induk dihubungkan dengan kutub positif, sedangkan untuk mesin las DC polaritas terbalik $(\mathrm{DC}+)$ digunakan bila titik cair bahan induk rendah dan kapasitas kecil, untuk pemegang elektrodanya dihubungkan dengan kutup positif dan logam induk dihubugkan dengan kutub negatif. Tidak semua logam memiliki sifat mampu las yang baik. Bahan yang mem- punyai sifat mampu las yang baik diantara- nya adalah baja karbon rendah. Baja ini dapat dilas dengan las busur elektroda terbungkus, las busur redam dan las MIG (las logam gas mulia). Baja karbon rendah biasa digunakan untuk pelat-pelat tipis dan konstruksi umum (Wiryosumarto, 1988).

Penyetelan kuat arus pengelasan akan mempengaruhi hasil las. Bila kuat arus yang digunakan terlalu rendah akan menyebabkan sukarnya penyalaan busur listrik. Busur listrik yang terjadi menjadi tidak stabil. Panas yang terjadi tidak cukup untuk melelehkan elektroda dan bahan dasar sehingga hasilnya merupakan rigi-rigi las yang kecil dan tidak rata serta penembusan kurang dalam. Sebaliknya bila kuat arus terlalu tinggi maka elektroda akan menair terlalu cepat dan akan menghasilkan permukaan las yang lebih lebar dan penembusan yang dalam sehingga menghasilkan kekuatan tarik yang rendah dan menambah kerapuhan dari hasil pengelasan (Arifin, 1997).

Kasus yang terjadi di Bekasi rel kereta api yang patah di antara Stasiun Bekasi dan Stasiun Kranji, Jawa Barat, diduga diakibatkan karena kerusakan pada sambungan las. Akibatnya, rel putus dan satu bagian penyok ke arah bawah. Menurut seorang petugas maintenance PT KA yang memperbaiki sambungan rel tersebut, rel patah tepat di sambungan yang menggunakan perekat las di sisi sebelah kanan (dari arah Jakarta), sehingga satu bagian penyok ke bawah di antara bantalan beton, dan satu bagian lain normal. Posisi rel yang patah sekira 300 meter menjelang Stasiun Kranji dari arah Bekasi. "Ini kami sedang perbaiki. Rel sudah retak tidak kuat. Mau diratakan dulu," ungkap 
seorang petugas di lokasi, Minggu (11/7/20). Sebanyak delapan petugas tampak memperbaiki bagian rel agar mudah diratakan. Posisi rel penyok ke bawah sekira 5 centimeter.

Kekuatan hasil lasan dipengaruhi oleh perlakuan pendinginan, besar busur, kecepatan pe- ngelasan, besarnya penembusan dan polaritas listrik. Penentuan besarnya kuat arus dalam penyambungan logam menggunakan las busur mempengaruhi efisiensi pekerjaan dan bahan las.

\section{METODE PELAKSANAAN}

Penelitian ini merupakan penelitian jenis eksperimental, untuk memperoleh deskripsi tentang pengaruh variasi pendinginan dan struktur mikro pada pengelasan baja karbon rendah. Data yang telah diperoleh dari hasil pengujian kekuatan tarik selama penelitian diisikan pada lembar observasi, data yang didapat dianalisis mengguna- kan analisis deskriptif. Pada uji kekuatan lentur menggunakan spesimen yang sama, terlebih dahulu dilakukan lentur.

Objek penelitian pengelasan yang di- pakai adalah baja karbon rendah, yang memiliki ukuran setiap spesimen dengan panjang 150 $\mathrm{mm}$, lebar $20 \mathrm{~mm}$, dan tebal $\mathrm{mm}$, sehingga total semua spesimen adalah 3 buah yang mengacu pada ISO 178-2003 Bending Three Point. Sedangkan spesimen uji Bending berdimensi panjang $150 \mathrm{~mm}$, lebar $20 \mathrm{~mm}$ dan tebal $\mathrm{mm}$. Setiap variasi mendapat perlakuan pendinginan yang berbeda. Sebagai spesimen pembanding diambil 1 foto spesimen logam induk. Instrumen penelitian yang digunakan adalah lembar observasi yang berisi data angka kekuatan Tekan pada baja yang telah mengalami proses pengelasan dengan variasi Pendinginan.

Prosedur pengumpulan data pada penelitian ini dengan mempersiapkan bahan baja karbon rendah, mesin las SMAW, oli mesin, air coolent, dan air Aqua. Pengambilan data dimulai dengan:
1. Material yang digunakan adalah baja karbon rendah SS400 mengacu pada standarisasi Japanese Industrial Standard (JIS).

2. Dimensi ukuran spesimen uji bending panjang $150 \mathrm{~mm}$, lebar $20 \mathrm{~mm}$, tebal $\mathrm{mm}$ mengacu pada standarisasi ASTM E23-02.

3. Elektroda yang digunakan adalah LB 52-U dengan diameter elektroda 2,6 $\mathrm{mm}$ mengacu pada standarisasi American Welding Society.

4. Posisi pengelasan yang dilakukana adalah posisi Down Hand (bawah tangan).

5. Variasi arus listrik yang digunakan adalah $70 \mathrm{~A}, 80 \mathrm{~A}$

6. Kampuh pengelasan yang digunakanan kampuh $\mathrm{V}$, dengan jarak celah 2,6 mm, tinggi akar kaki pengelasan $3 \mathrm{~mm}$.

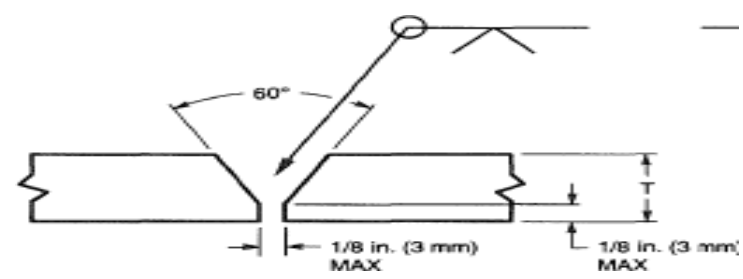

Gambar 1. Spesimen uji bending standarisasi

Spesimen pengelasan berukuran panjang $150 \mathrm{~mm}$, lebar $20 \mathrm{~mm}$, tebal mm. Kemudian melaksanakan pengelasan sesuai dengan Welding Procedure Spesification (WPS). Benda kerja hasil pengelasan kemudian dibentuk menjadi spesimen uji bending. Pembentukan spesimen ini dilakukan dengan menggunakan mesin Cutting Whell.

Langkah-langkah pengujian bending adalah:

1. Menghidupkan mesin dan komputer.

2. Menginput data yaitu tebal dan lebar spesimen yang akan diuji bending.

3. Memasang spesimen uji pada grips.

4. Memulai uji bending dengan menekan tombol start pada layar monitor.

5. Setelah spesimen patah, putar panel pada manual kontrol posisi nol.

6. Melepas spesimen yang sudah patah setelah pengujian. 
7. Melihat hasil penguji Bending di computer

\section{HASIL DAN PEMBAHASAN}

\section{Uji Bending}

Berdasarkan hasil pengujian lentur baja karbon rendah yang telah mengalami proses pengelasan SMAW dengan variasi Pendinginan diperoleh angka lentur baja karbon rendah yang dapat dilihat pada gambar dan table di bawah ini.

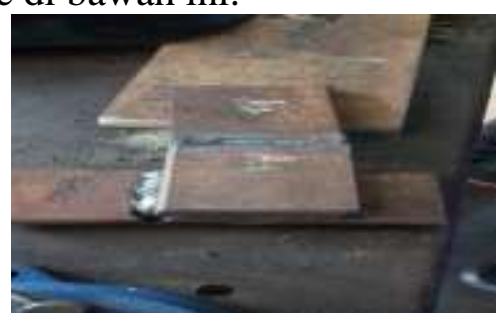

Gambar 2. Spesimen Saat Proses Pengelasan

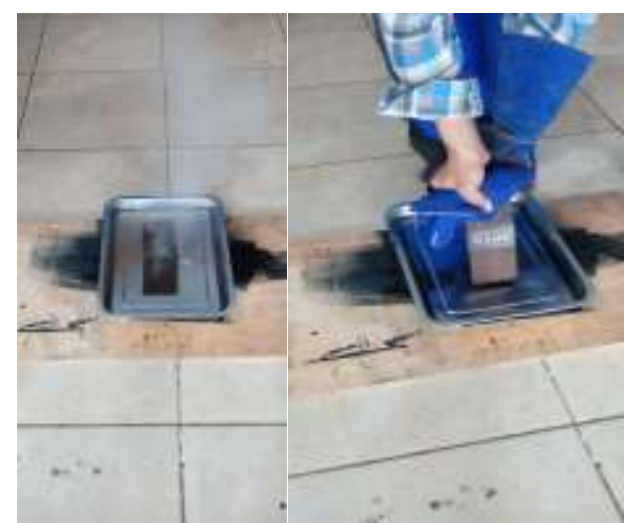

Gambar 3. Spesimen Saat Proses Pendinginan

Tabel 1. Logam Induk Pengisian

Pengukuran Akar

Pengukuran Sudut V

$2.0 \mathrm{~mm}$

Pengukuran Celah Las Pengelasan

Pengukuran Temperatur Sebelum Pengelasan

Pengukuran Suhu Setelah di dinginkan

Waktu Pendinginan

Pengukuran Ketinggina Root pass

Pengukuran Ketinggian Las -Lasaan Caping

$2,7 \mathrm{~mm}$

Tabel 2. Parameter Pengelasan

\begin{tabular}{lcc}
\hline \multicolumn{1}{c}{ Nama } & \multicolumn{2}{c}{ Keterangan } \\
\hline Materail Spesifikasi & ST 37 & \\
Tebal & Mm \\
AWS Clasification & F.7018 \\
Filler Metal Diameter & $2,6 \mathrm{~mm}$ \\
Posisi Pengelasan & $1 \mathrm{G}$ \\
\hline \multicolumn{2}{c}{ Parameter } & \\
\hline Number & 1 (root) & Layar (fill \& caping) \\
Proses & SMAW & 5,284 \\
Travel/Speed & 5,284 & 5,284 \\
Amper & 80 & 80 \\
Voltage & 220 & 220 \\
Elektroda Diameter & $2,6 \mathrm{~mm}$ & $2,6 \mathrm{~mm}$ \\
Polaritas AC/DC & DC+) & DC+) \\
\hline
\end{tabular}

\section{Pengamatan Pengujian Bending}

Pada penelitian ini, pengambilan foto dilakukan pada 3 bagian pada sambungan las.
Bagian pertama pada logam induk. Pengambilan foto pada logam induk digunakan sebagai pembanding (raw materi- als). Bagian 
kedua diambil pada daerah HAZ dan bagian ketiga pada logam las.

\section{Pengaruh Variasi Pendinginan terhadap Kekuatan Uji Bending Sambungan Las}

Hasil penelitian ini menunjukkan bahwa adanya pengaruh variasi kuat arus terhadap kekuatan lentur pada sambungan las. Bila hasil pengujian lentur raw, maka nilai Tegangan dengan Pendinginan Oli mengalami penaiakan yaitu 32116,16. Sedangkan Pendinginan denan Coolant mengalami Penurunan 13144,9 N.
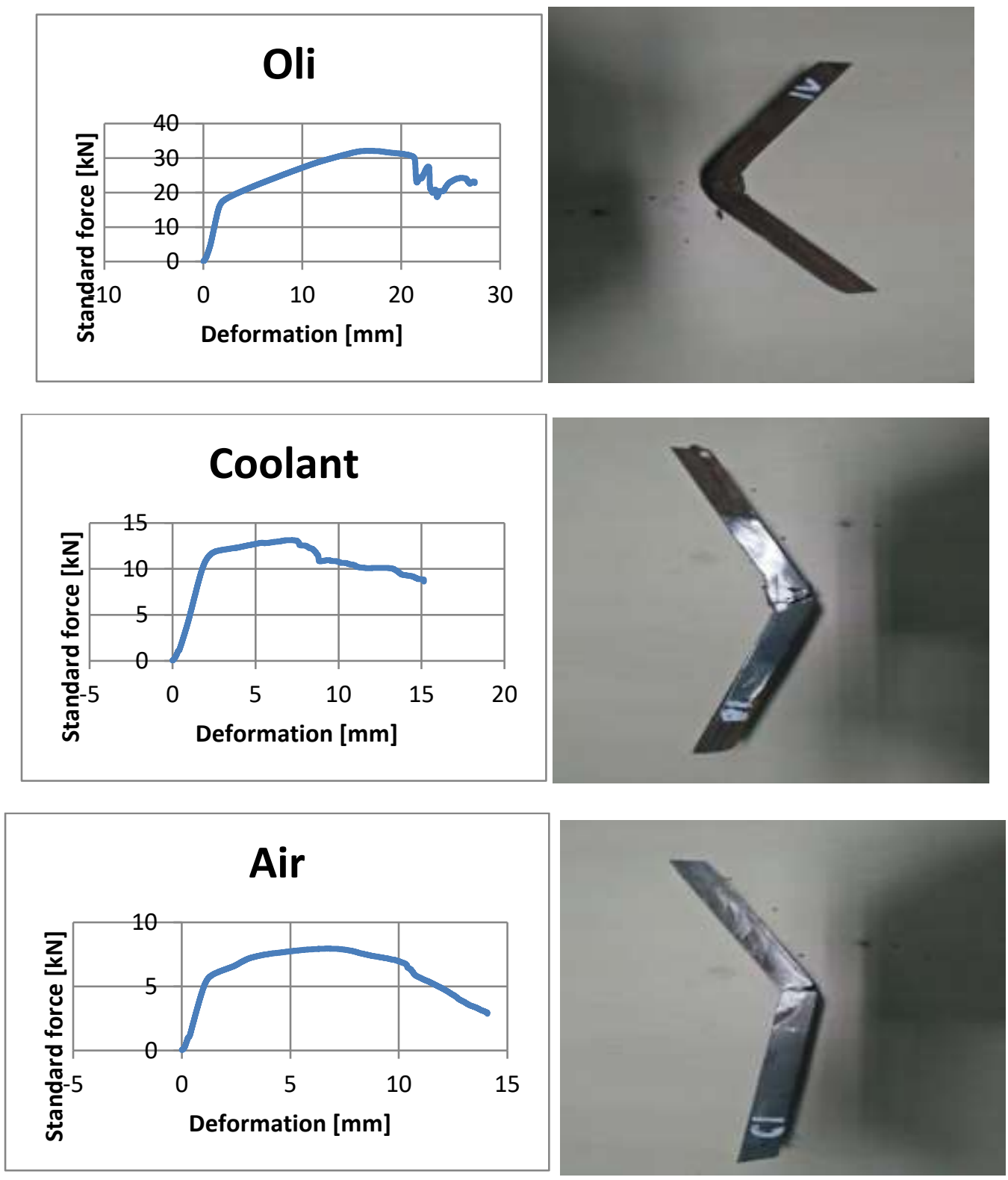

Gambar 4. Hasil Pengujian bending

Tabel 3. Hasil Pengujian Bending

\begin{tabular}{lccccccccccc}
\hline & $\mathrm{N}$ & $\mathrm{MPa}$ & $\%$ & $\mathrm{MPa}$ & $\mathrm{MPa}$ & $\mathrm{MPa}$ & $\mathrm{MPa}$ & $\mathrm{MPa}$ & $\mathrm{mm}$ & $\mathrm{mm}$ & $\mathrm{mm}$ \\
\hline Oli & 32118 & 1777 & 11 & & 317 & 862 & 1075 & 1183 & 11 & 24 & 100 \\
Coolant & 13145 & 308 & 7 & & 40 & 111 & 257 & 283 & 17 & 24 & 100 \\
\hline
\end{tabular}




\begin{tabular}{lllllllllll}
\hline Air & 7951 & 382 & 5 & 162 & 286 & 338 & 365 & 12 & 24 & 100 \\
\hline
\end{tabular}

\section{KESIMPULAN DAN SARAN}

Variasi Perlakuan Pendinginan pengelasan memberikan pengaruh terhadap nilai kekuatan tekan sambungan las. Kekuatan bending sambungan las. nilai bending dengan pendinginan Oli mengalami kenaikan yaitu 32118,16 N. Sedangkan dengan Pendinginan dengan Coolant mengalami Penurunan 1144,9 N. Pada Air Mengalami penurunan 7950,92 N. Variasi Pendinginan memberikan pengaruh terhadap Kekuatan lentur pada daerah HAZ dan logam las. Bahawa pendinginan Menggunakan Oli lebih kuat saat di Bending dibandaingkan Pendinginan menggunakan Air dan Coolant.

Disarankan menggunakan elektroda LB52-U untuk mengahasilkan sambungan las dengan kekuatan Bending yang baik; Perlu diperhatikan tentang pemilihan kuat arus pada pengelasan SMAW agar mendapatkan hasil las dengan sifat mekanik yang baik. Disarankan menggunakan kuat arus 80 Ampere untuk mengahasilkan sambungan las dengan kekuatan Bending yang baik; Perlu penelitian lebih lanjut tentang pengaruh variasi kuat arus pada pengelasan SMAW untuk menghasilkan sifat mekanik seperti kekerasan, kekuatan tekuk; dan Perlu penelitian dengan spesimen lebih banyak sehingga mendapat- kan hasil yang lebih teliti

\section{DAFTAR PUSTAKA}

Adam, Kaharuddin. 2011. Faktor Perpatah- an dan Kelelahan pada Kekuatan Bahan Material. Jurnal Teknik Mesin. 6-12.
Alip, Muhammad. 1989. Teori dan Praktik Las. Jakarta: Proyek pengembangan lembaga pendidikan tenaga kependidikan Jakarta

Aljufri. 2013. Ketanggunhan Material Baja AISI 50 Akibat Pembebanan Impact Hasil Pengelasan SMAW yang Telah Mengalami Proses Hardening dan Tanpa Proses Hardening. Skripsi ti- dak diterbitkan. Aceh: Fakultas Teknik Universitas Malikussaleh.

Pembebanan Impact Hasil Pengelasan SMAW yang Telah Mengalami Proses Hardening dan Tanpa Proses Hardening. Skripsi tidak diterbitkan. Aceh: Fakultas Teknik Universitas Malikussaleh.

ASTM Internasional (E8/E8M - 09). Stan- dard Test Methods for Tension Testing of Metalic Materials. 20. United States of America.

Raharjo, Samsudi \& Rubijanto J.P. 2012. Variasi Arus Listrik Terhadap Sifat Mekanis Sambungan Las Shielding Metal Arc Welding (SMAW). Jurnal FT UMS, 1412-9612.

Santosa, Joko. 2006. Pengaruh Arus Pengelasan Terhadap Kekuatan Tarik dan Ketangguhan Las SMAW dengan Elektroda E7018. Skirpsi Tidak Diterbitkan. Semarang. Universitas Negeri Semarang.

Saroso. 1980. Pedoman Melas Listrik. Jakarta: Djambata 